\title{
Land cover change and eco-environmental quality response of different geomorphic units on the Chinese Loess Plateau
}

\author{
SONG Yongyong ${ }^{1}$, XUE Dongqian $^{1 *}$, DAI Lanhai ${ }^{1}$, WANG Pengtao ${ }^{2}$, HUANG Xiaogang ${ }^{1}$, \\ XIA Siyou ${ }^{3}$ \\ ${ }^{1}$ School of Geography and Tourism, Shaanxi Normal University, Xi'an 710119, China; \\ ${ }^{2}$ School of Tourism \& Research Institute of Human Geography, Xi'an International Studies University, Xi'an 710128, China; \\ ${ }^{3}$ School of Geography Science, Nanjing Normal University, Nanjing 210023, China
}

\begin{abstract}
Land cover in the Chinese Loess Plateau has undergone dramatic changes since the late 1980s. Revealing the trend in land cover change and eco-environmental quality response of different geomorphic units in this stage is a realistic requirement for promoting sustainable development of the Chinese Loess Plateau. Based on the data of geomorphic units and land cover in 1990, 2000, 2010 and 2018 of the Chinese Loess Plateau, we studied the trend of land cover change and eco-environmental quality response of different geomorphic units by using a significance index of land cover change, a proportion index of land cover change and an eco-environmental response model. The results indicated that from 1990 to 2018, the areas of forestland and construction land substantially increased, whereas those of cropland, grassland, wetland and unused land considerably decreased. Land cover change exhibited large geomorphic differences, and the main conversion of land cover was from cropland into other land types. Unstable trend of land cover change in the loess tablelands and sandy loess hills declined, whereas the unstable trends in the other geomorphic units enhanced. Eco-environmental quality varied among different geomorphic units. The expansion of construction land and degradation of forestland, grassland and wetland resulted in the deterioration of eco-environmental quality. The conversion of cropland and unused land into forestland and grassland, and the conversion of grassland into forestland were the main factors that drove the improvement of eco-environmental quality. The findings of this study may provide theoretical reference and support decision making for the optimization of land use structure and the improvement of eco-environmental quality on the Chinese Loess Plateau.
\end{abstract}

Keywords: cropland; degradation; eco-environmental quality index; grassland; human activity; unused land; relative ecological value

Citation: SONG Yongyong, XUE Dongqian, DAI Lanhai, WANG Pengtao, HUANG Xiaogang, XIA Siyou. 2020. Land cover change and eco-environmental quality response of different geomorphic units on the Chinese Loess Plateau. Journal of Arid Land, 12(1): 29-43. https://doi.org/ 10.1007/s40333-019-0031-8

\section{Introduction}

Land use/cover change (LUCC), as a key link among four spheres (atmosphere, hydrosphere, biosphere and lithosphere) of the Earth's system (Mayer and Turner, 1994; Reid et al., 2010), is the most direct manifestation of the role of human activity on the Earth's system (Mooney et al., 2013;

\footnotetext{
*Corresponding author: XUE Dongqian (E-mail: xuedq@snnu.edu.cn)

Received 2018-08-23; revised 2019-10-15; accepted 2019-11-11

(C) Xinjiang Institute of Ecology and Geography, Chinese Academy of Sciences, Science Press and Springer-Verlag GmbH Germany, part of Springer Nature 2020
} 
Lawler et al., 2014) and an important indicator of the response of human activity to global land cover change (Deng et al., 2014; Wu et al., 2014; Ning et al., 2018). The global land cover pattern has been dramatically changing since the 1950s due to the rapid growth of population and the fast development of social economy, and this situation has elicited widespread concern (Lambin et al., 1995; Turner et al., 1995; GLP, 2005). In China, sustained and rapid development of social economy, accelerations of industrialization and urbanization and implementation of national and regional development and ecological protection strategies have considerably affected the spatial patterns of land cover change since the end of the $20^{\text {th }}$ century (Liu et al., 2014; Song and Deng, 2017). LUCC, with the coupled human-natural system as its core, has become an important factor for studies of the global climate and environmental changes.

Studies on land cover changes, its driving factors and effects on the ecological environments have been extensively conducted (Kalnay and Cai, 2003; Turner et al., 2007; Zhang et al., 2014). For example, Waisanen et al. (2002) used cropland-related data to analyze the spatio-temporal variations in arable land in the United States from 1790 to 1997. Ge et al. (2008) examined the variations of land use change in China in the past 300 years by using the historical land data. Liu et al. (2014) described the spatial distribution pattern of land cover change in China by using the LUCC transfer matrix and land dynamic degree model. Land cover change is driven by many factors. On a large regional scale, natural environmental factors, such as climate, hydrology, soil and topography play important roles (Bičík et al., 2015). And their impacts are long and stable (Chen et al., 2016). On a small regional scale, where differences in climatic factors are small, topography and geomorphology are the key factors that restrict human activity and influence land cover changes (Verbuerg and Chen, 2000). Moreover, the relationships between topographical factors, such as elevation, slope, slope direction and land use changes were studied (Zhong et al., 2012; Li et al., 2013; Li et al., 2016). However, the data used in illuminating the relationships is based on macroscopic geomorphic unit (GAPRCEC, 2009; Zhao et al., 2016), which cannot reflect the geomorphic structures on a regional scale (He et al., 2016).

The Chinese Loess Plateau has complex geomorphic units, and typical and unique loess geomorphologies, such as tablelands, beams and mounds. The region has become one of the world's most heavily eroded areas due to the influence of global climatic changes and long-term disturbance by human activities (Shi and Shao, 2000). In the late 1980s, Chinese government promoted regional vegetation restoration and ecological reconstruction projects (Wang et al., 2016; Liu et al., 2017; Bryan et al., 2018). However, with the implementation of the China's Western Region Development Strategy and the National Energy Security Strategy in China, rapid urbanization and high-intensity energy resource development have exerted great pressure on the local ecological environment, thus resulting in environmental pollution, vegetation destruction and soil erosion in the Loess Plateau, China (CSNR, 2018). Geomorphology, the basic factor that affects human activities, directly influences land cover and land carrying capacity, controls the distribution of water, heat and sunlight resources and determines the direction of land cover change (CAS and CNGEC, 1980; Brierley and Stankoviansky, 2003; Luo et al., 2014). Therefore, it is necessary to study the process of regional changes of ecological environment to reveal the direction of land cover change and the response of ecological environment of different geomorphic units.

Using the significance index of land cover change, proportion index of land cover change and eco-environmental response model, this study aimed to (1) reveal land cover change and its dynamic conversion process before and after the implementation of converting cropland into forest and grassland; (2) discuss the process and possible causes of land cover change of different geomorphic units; and (3) examine the evolution of eco-environmental quality and its driving factors of different geomorphic units. The findings of this study will elucidate the relationships among geomorphology, land cover change and eco-environmental quality, and provide theoretical reference for the improvement of ecological restoration and sustainable development on the Chinese Loess Plateau. 


\section{Materials and methods}

\subsection{Study area}

The Loess Plateau is located in the upper and middle reaches of the Yellow River in northern China $\left(32^{\circ}-41^{\circ} \mathrm{N}, 101^{\circ}-114^{\circ} \mathrm{E}\right)$. It extends to the Yinshan Mountains in the north, the Qinling Mountains in the south, the Taihang Mountains in the east and the Wushaoling-Sun Moon Mountain in the west. It covers a total area of $62.46 \times 10^{4} \mathrm{~km}^{2}$. The plateau is approximately 1300 $\mathrm{km}$ long from east to west and approximately $800 \mathrm{~km}$ wide from north to south, with an average elevation of 1500-2000 m a.s.l. It covers the areas of Shanxi Province and Ningxia Hui Autonomous Region and parts of areas of Shaanxi, Henan, Gansu, Qinghai provinces and Inner Mongolia Autonomous Region (Wang, 2017). This area is a sub-humid and semi-arid zone with a temperate monsoon climate, a mean annual precipitation of $200-700 \mathrm{~mm}$ and an annual mean temperature of $9^{\circ} \mathrm{C}-12^{\circ} \mathrm{C}$ (Gao et al., 2016). Under the long-term disturbances of climate change and human activities, severe soil erosion occurs in the Loess Plateau. Soil erosion area is $4.72 \times 10^{5} \mathrm{~km}^{2}$ and water erosion amount is greater than $8000 \mathrm{t} /\left(\mathrm{km}^{2} \cdot \mathrm{a}\right)$ with an area of $9.12 \times 10^{4}$ $\mathrm{km}^{2}$, thereby resulting in the severe sediments in the lower reaches of the Yellow River (Zhao et al., 2013).

\subsection{Data sources}

Data of area of the Loess Plateau were obtained from an investigation of the Chinese Academy of Sciences (Wang, 2017). Data of major rivers were obtained from the national geographical database (http://www.web map.cn). Digital elevation model data with a spatial resolution of $90 \mathrm{~m}$ were provided by Data Center for Resources and Environmental Sciences, Chinese Academy of Sciences (http://www.resdc.cn).

Data of geomorphic units were referenced from Yang (1995; http://loess.geodata.cn), which were divided into 10 types, i.e., loess tableland (LT), river alluvial plain (RAP), loess beam hill (LBH), loess mound hill (LMH), loess valley hill (LVH), loess hills of intermountain basin (LHIB), sandy loess hill (SLH), sand blown hill (SBH), soil stone hill (SSH) and soil stone mountain (SSM; Fig. 1a). Among the 10 types of geomorphic units, SSM had the largest area, accounting for $25.37 \%$ of the total, and SLH had the smallest area, accounting for only $3.12 \%$ (Fig. 1b).

(a)

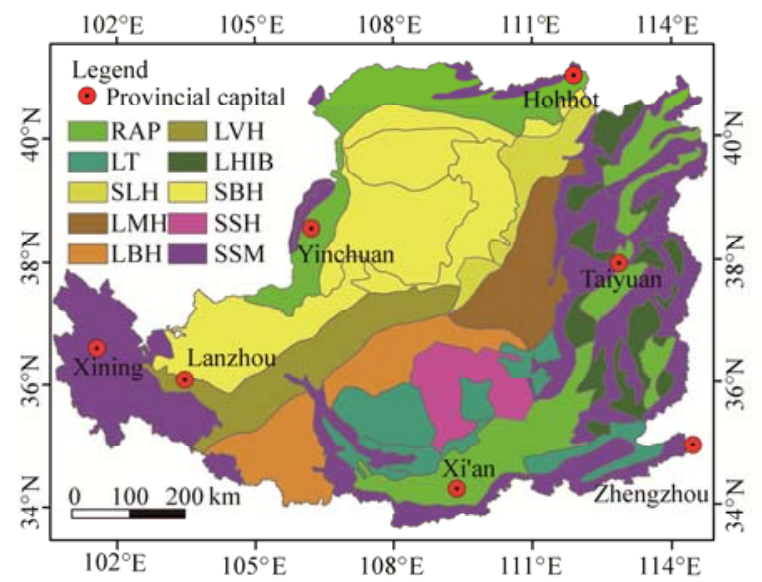

(b)

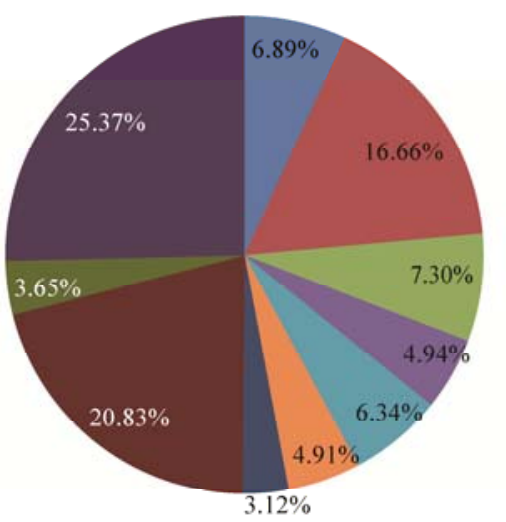

Fig. 1 Spatial distribution (a) and area proportion (b) of 10 types of geomorphic units on the Chinese Loess Plateau. LT, loess tableland; RAP, river alluvial plain; LBH, loess beam hill; LMH, loess mound hill; LVH, loess valley hill; LHIB, loess hills of intermountain basin; SLH, sandy loess hill; SBH, sand blown hill; SSH, soil stone hill; SSM, soil stone mountain. The abbreviations are the same as in Figures 4 and 5 and Table 3.

Data of land cover were referenced from the Data Center for Resources and Environmental Sciences, Chinese Academy of Sciences. Landsat TM/ETM images in 1990, 2000, 2010 and 2018 
with a spatial resolution of $30 \mathrm{~m}$ were utilized as as the main data source combined with a field investigation. According to the classification system of land cover, this study classified the study area into 6 types of land cover, namely, cropland, forestland, grassland, wetland, construction land and unused land (Fig. 2). To evaluate the applicability of these data in the Loess Plateau, we firstly superimposed the land cover maps of each period and then extracted the unaltered areas, from which 500 points were randomly collected by computer, and finally superimposed them with a high-resolution satellite image from Google Earth for the accuracy test. The interpretation accuracy was $87.6 \%$ that could meet the requirement for mapping accuracy (Janssen et al., 1994; Li et al., 2016).

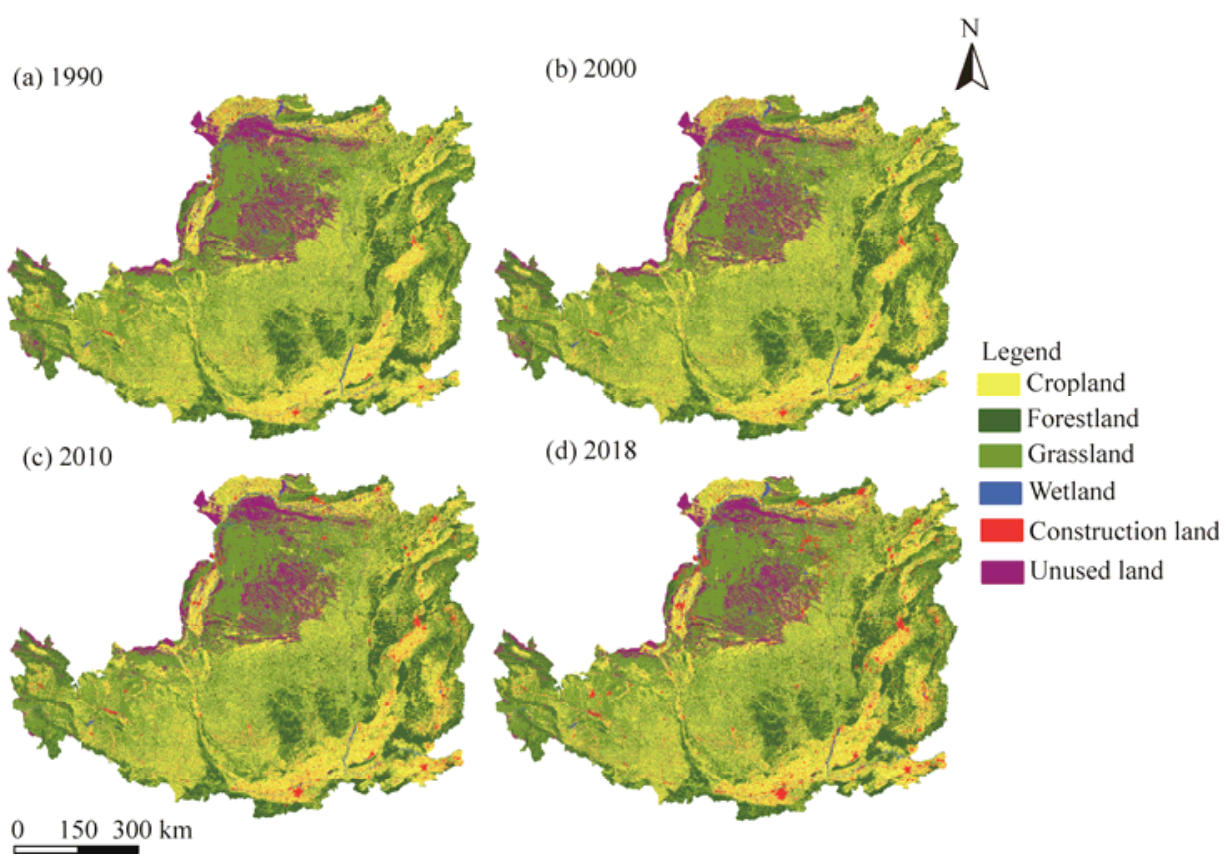

Fig. 2 Land cover changes on the Chinese Loess Plateau in 1990 (a), 2000 (b), 2010 (c) and 2018 (d)

\subsection{Methods}

2.3.1 Significance index of land cover change

The significance index of land cover change refers to the degree of importance of regional land cover change and is utilized to identify the main types of land cover change (Zhao et al., 2016). The significance index of land cover change can be calculated as follows:

$$
\begin{gathered}
C_{i}=A_{i} / A \times 100 \%, \\
A=\sum_{i=1}^{n} A_{i},
\end{gathered}
$$

where $C_{i}$ is the significance index of land cover change (\%), ranging from $0 \%$ to $100 \%$; $A_{i}$ is the cover change area of type $i$ land $\left(\mathrm{km}^{2}\right)$; and $A$ is the total area of land cover change $\left(\mathrm{km}^{2}\right)$. The larger the $C_{i}$ value is, the more dominant the land cover change of type $i$ land is. In analyses, $C_{i}$ values are sorted in descending order from large to small, and the land cover change types with cumulative values of $C_{i}$ greater than $70 \%$ are statistically plotted to identify the main types of land cover change in the study area (Zhao et al., 2016).

\subsubsection{Proportion index of land cover change}

The proportion index of land cover change refers to the percentage of land cover change area in the total regional area and is used to depict the intensity of land cover change (Luo et al., 2014). The proportion index of land cover change can be calculated as follows:

$$
D=A / S \times 100 \%,
$$

where $D$ is the proportion index of land cover change (\%), ranging from $0 \%$ to $100 \%$; $A$ is the 
area of land cover change of different land types $\left(\mathrm{km}^{2}\right)$; and $S$ is the total regional area $\left(\mathrm{km}^{2}\right)$. The larger the $D$ value is, the more drastic the land cover change is.

\subsubsection{Eco-environmental quality index (EQI)}

The EQI is quantitatively expressed as the overall state of regional environmental quality (Lu et al., 2013), which is defined as follows:

$$
\mathrm{EV}_{t}=\sum_{i=1}^{n} \mathrm{LU}_{i} \times V_{i} / \mathrm{TA}
$$

where $\mathrm{EV}_{t}$ is the eco-environmental quality index; $\mathrm{LU}_{i}$ is the area of the land cover type $i\left(\mathrm{~km}^{2}\right)$; $V_{i}$ is the relative ecological value of type $i$, which refers to the proportion relation of the ecosystem service value per unit area of different ecosystems (Song et al., 2018); TA is the total regional area $\left(\mathrm{km}^{2}\right)$; and $n$ is the number of land cover types. According to the coefficients of ecosystem service value of China's terrestrial ecosystem established by Xie et al. (2003), this study calculated the relative ecological values of different types of land cover in the Loess Plateau (Table 1).

Table 1 Relative ecological values of different types of land cover on the Chinese Loess Plateau

\begin{tabular}{ccccccc}
\hline Index & Cropland & Forestland & Grassland & Wetland & Construction land & Unused land \\
\hline $\begin{array}{c}\text { Coefficient of ecosystem } \\
\begin{array}{c}\text { service value } \\
\left(\mathrm{CNY} /\left(\mathrm{hm}^{2} \cdot \mathrm{a}\right)\right)\end{array}\end{array}$ & 6114.3 & $19,334.0$ & 6406.5 & $5,5489.0$ & 0.0 & 371.4 \\
$\begin{array}{c}\text { Relative ecological value } \\
\text { Relo }\end{array}$ & 0.110 & 0.348 & 0.116 & 1.000 & 0.000 & 0.007 \\
\hline
\end{tabular}

The change index of eco-environmental quality is utilized to express the change trend of regional eco-environmental quality and is calculated as follows:

$$
\mathrm{EI}=\mathrm{EV}_{t}-\mathrm{EV}_{t-1},
$$

where $\mathrm{EI}$ is the change index of eco-environmental quality; $\mathrm{EV}_{t}$ and $\mathrm{EV}_{t-1}$ are the EQI at the $t$ and $t-1$ periods, respectively. EI $>0$ indicates that the regional eco-environmental quality at a certain phase is improving, $\mathrm{EI}=0$ indicates stable, and $\mathrm{EI}<0$ means deteriorate.

\section{Results}

\subsection{Characteristics of land cover change}

The areas of forestland and construction land in the Loess Plateau considerably increased from 1990 to 2018, whereas the areas of cropland, grassland, wetland and unused land considerably decreased. The time series from 1990 to 2018 were divided into three periods (1990-2000, 2000-2010 and 2010-2018) in this study. In the three periods, the area of forestland continued to increase at an average annual increase rate of $0.12 \%$. The area of construction land presented a continuous expansion trend at an average annual increase rate of $2.45 \%$. The area of wetland decreased and then increased but showed an overall decreasing tendency. The area of cropland increased and then decreased, showing an overall decreasing tendency. The areas of unused land showed a continuous decreasing trend, and the grassland land tended to fluctuate downward. Land cover changes in Ningxia, Shaanxi, Shanxi and Henan regions were notable, whereas the changes were small in Qinghai, Gansu and Inner Mongolia regions (Fig. 3).

From 1990 to 2018, 30 types of land cover change were observed in the Loess Plateau, and the total area of land cover change was $95,151.90 \mathrm{~km}^{2}$, accounting for $15.17 \%$ of the total area of the Loess Plateau (Table 2). The area of land cover change from 1990 to 2000 was small and accounted for $2.14 \%$ of the total regional area; mutual conversions between grassland and cropland and between grassland and unused land were the main types of land cover change. The area of land cover change increased from 2000 to 2010 and accounted for $7.47 \%$ of the total regional area. Conversions from cropland into grassland, construction land and forestland land and mutual conversion between cropland and grassland were the main types of land cover change. The area of land cover change from 2010 to 2018 was large and accounted for $9.30 \%$ of the total 
regional area, mainly showing a significant expansion of construction land. Generally, land cover change was primarily converted from cropland into other land types in the Loess Plateau over the 28-year study period.

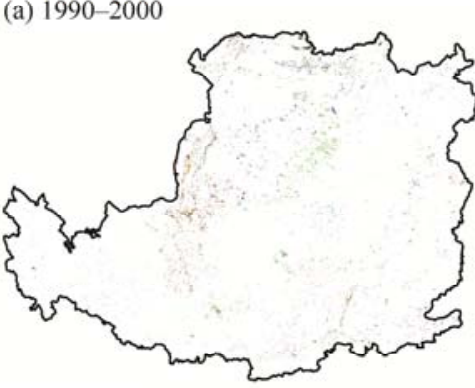

(c) 2010-2018

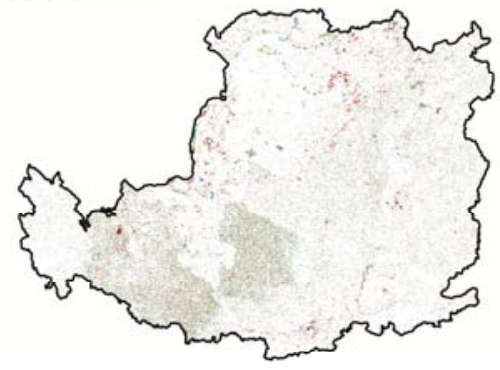

$\begin{array}{lll}0 \quad 160 \quad 320 & \mathrm{~km}\end{array}$
$\stackrel{N}{\Lambda}$

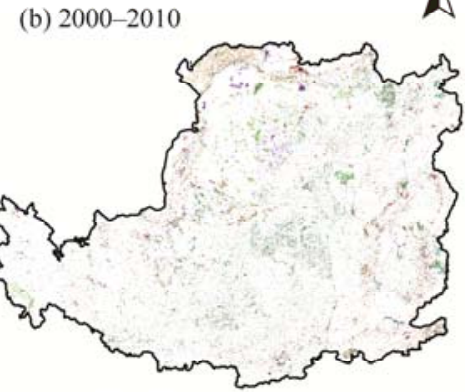

(d) 1990-2018

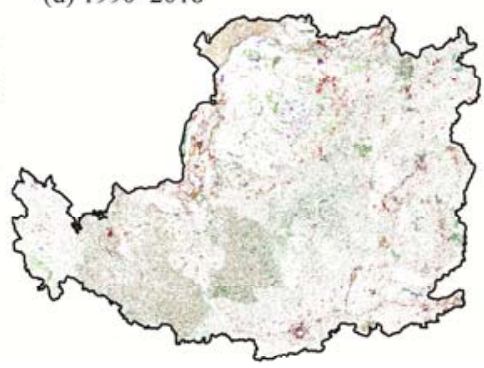

Legend

- Forestland into cropland - Grassland into cropland - Wetland into cropland

Construction land into cropland

Unused land into cropland - Cropland into forestland - Grassland into forestland Wetland into forestland Construction land into forestland - Unused land into forestland - Cropland into grassland - Forestland into grasslan - Wetland into grassland - Construction land into grassland Unused land into grassland - Cropland into wetland Eorestland into wetland Grassland into wetland - Construction land into wetland - Unused land into wetland

- Cropland into construction land

- Forestland into construction land - Grassland into construction land

-Wetland into construction land

Unused land into construction land - Cropland into unused land -Forestland into unused land - Grassland into unused land - Wetland into unused land - Construction land into unused land -Loess Plateau boundary

Fig. 3 Spatial distribution of land cover change on the Chinese Loess Plateau from 1990 to 2018

\subsection{Spatial-temporal patterns of land cover change of different geomorphic units}

\subsubsection{Significance index of land cover change}

From 1990 to 2018, the significance index of land cover change was remarkably different among different geomorphic units in the Loess Plateau. Six types of change trends, namely, stable, smoothly descending, quickly descending, quickly descending followed by stable, stable followed by quickly descending and stable followed by quickly descending and then stable were found (Fig. 4). Over the 28-year study period, the main types of land cover changes in the 5 geomorphic units, namely, LT, LBH, LMH, SLH and SSH, were the conversion from cropland into grassland, and the significance indices for these geomorphic units were $37.12 \%$ for LT, $41.79 \%$ for $\mathrm{LBH}$, $36.61 \%$ for LMH, $34.05 \%$ for SLH and $25.81 \%$ for SSH. However, the main types of land cover changes were the conversion from grassland into cropland of the 3 geomorphic units of LVH, LHIB and SSM, and the significance indices for these geomorphic units were $38.29 \%$ for LVH, $20.46 \%$ for LHIB and $18.16 \%$ for SSM. Meanwhile, the main types of land cover changes in another 2 geomorphic units, namely, RAP and SBH, were the conversion from cropland into construction land and from unused land into grassland, respectively, and the significance indices for these geomorphic units were $23.97 \%$ and $25.12 \%$, correspondingly.

From 1990 to 2000, the change trend of significance indices of LT, RAP, LHIB and SBH were smoothly descending. For $\mathrm{LMH}, \mathrm{LVH}$ and $\mathrm{SSH}$, their indices showed quickly descending trends. For LBH, SLH and SSM, their indices showed a quickly descending followed by stable trend. From 2000 to 2010, the significance indices of LHIB, SBH and SSM showed a smoothly descending trend. For LT, LBH, SLH and SSH, their indices showed a quickly descending followed by stable trend. For LMH and LVH, their indices showed a rapidly descending trend. For RAP, the value of significance index showed a stable trend before rapidly descending and finally became stable. From 2010 to 2018, the significance indices of LBH, LMH and LVH showed a steady trend. For RAP, SBH and SSH, their indices showed a smoothly descending 
trend. For SLH and SSM, their indices showed a stable followed by quickly descending trend. For LT and LHIB, their indices showed a stable followed by quickly descending and then stable trend.

Table 2 Types of land cover change on the Chinese Loess Plateau from 1990 to 2018

\begin{tabular}{|c|c|c|c|c|}
\hline Phase & Type of conversion & Area of conversion $\left(\mathrm{km}^{2}\right)$ & $C_{i}(\%)$ & $D(\%)$ \\
\hline \multirow[t]{9}{*}{$1990-2000$} & Grassland into cropland & 3477.24 & 25.93 & 0.55 \\
\hline & Unused land into grassland & 2216.95 & 16.54 & 0.35 \\
\hline & Grassland into unused land & 1396.36 & 10.41 & 0.22 \\
\hline & Cropland into grassland & 1180.17 & 8.80 & 0.19 \\
\hline & Cropland into construction land & 1034.60 & 7.72 & 0.17 \\
\hline & Forestland into grassland & 860.72 & 6.42 & 0.14 \\
\hline & Cumulative area of conversions & $10,166.04$ & 75.82 & 1.62 \\
\hline & Others & 3241.40 & 24.18 & 0.52 \\
\hline & Total (30 types) & $13,407.45$ & 100.00 & 2.14 \\
\hline \multirow[t]{10}{*}{$2000-2010$} & Cropland into grassland & 9221.81 & 19.69 & 1.47 \\
\hline & Grassland into cropland & 7453.21 & 15.91 & 1.19 \\
\hline & Cropland into construction land & 5604.95 & 11.96 & 0.89 \\
\hline & Unused land into grassland & 4059.94 & 8.67 & 0.65 \\
\hline & Grassland into forestland & 3148.83 & 6.72 & 0.50 \\
\hline & Cropland into forestland & $3,096.33$ & 6.61 & 0.49 \\
\hline & Grassland into unused land & 2250.93 & 4.80 & 0.36 \\
\hline & Cumulative area of conversions & $34,836.00$ & 74.36 & 5.55 \\
\hline & Others & $12,010.17$ & 25.64 & 1.91 \\
\hline & Total (30 types) & $46,846.17$ & 100.00 & 7.47 \\
\hline \multirow[t]{9}{*}{$2010-2018$} & Cropland into grassland & $14,673.72$ & 25.13 & 2.34 \\
\hline & Grassland into cropland & $13,474.82$ & 23.08 & 2.15 \\
\hline & Cropland into construction land & 4323.83 & 7.41 & 0.69 \\
\hline & Grassland into forestland & 4040.14 & 6.92 & 0.64 \\
\hline & Forestland into grassland & 3554.50 & 6.09 & 0.56 \\
\hline & Grassland into construction land & 2562.50 & 4.39 & 0.41 \\
\hline & Cumulative area of conversions & $42,629.50$ & 73.02 & 6.79 \\
\hline & Others & $15,749.95$ & 26.98 & 2.51 \\
\hline & Total (30 types) & $58,379.45$ & 100.00 & 9.30 \\
\hline \multirow[t]{9}{*}{$1990-2018$} & Cropland into grassland & $20,489.52$ & 21.53 & 3.27 \\
\hline & Grassland into cropland & $19,614.42$ & 20.62 & 3.13 \\
\hline & Cropland into construction land & 9725.86 & 10.22 & 1.55 \\
\hline & Unused land into grassland & 6806.69 & 7.15 & 1.09 \\
\hline & Grassland into forestland & 6658.70 & 7.00 & 1.06 \\
\hline & Forestland to grassland & 4917.78 & 5.17 & 0.78 \\
\hline & Cumulative area of conversions & $68,212.97$ & 71.69 & 10.88 \\
\hline & Others & $26,938.93$ & 28.31 & 4.29 \\
\hline & Total (30 types) & $95,151.90$ & 100.00 & 15.17 \\
\hline
\end{tabular}



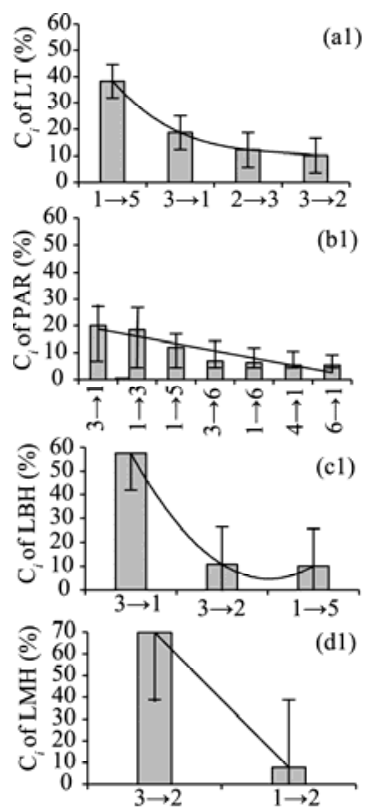

○ 60.
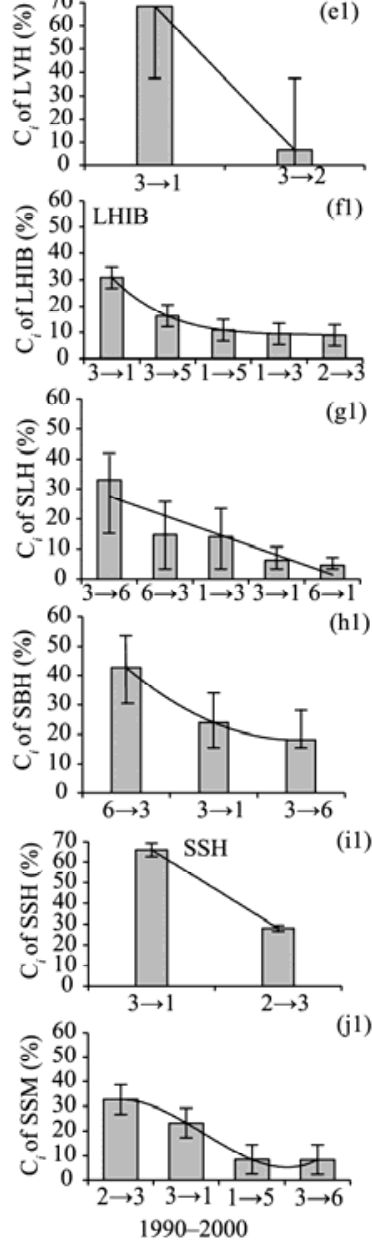

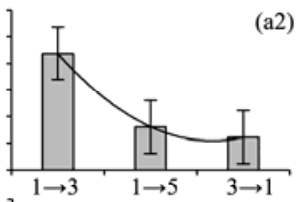

(b2)
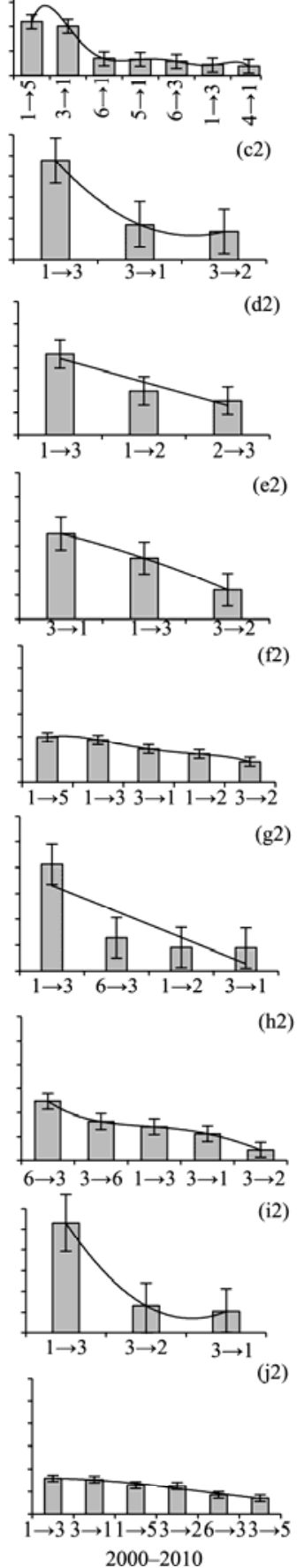

(i2)

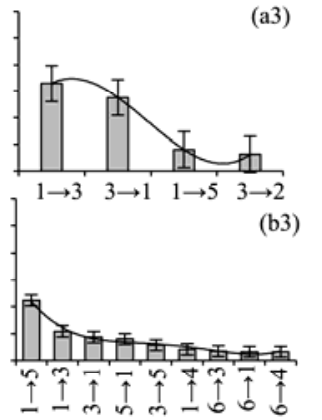

(c3)

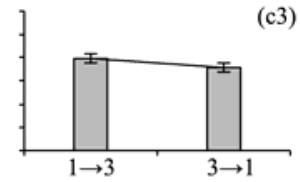

(d3)

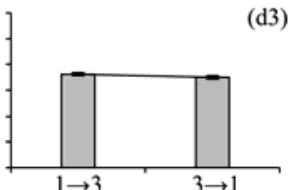

(e3)

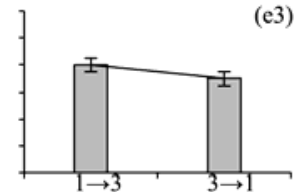

(f3)

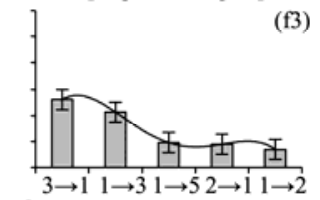

(g3)
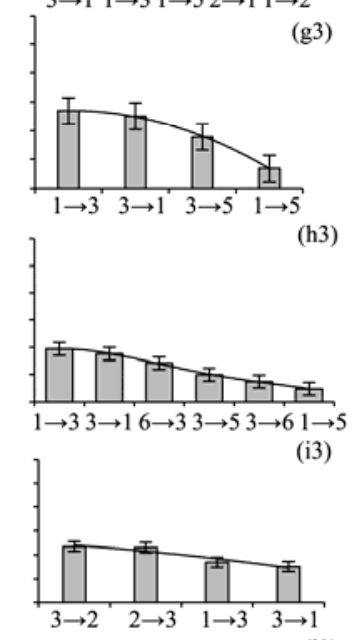

(j3)

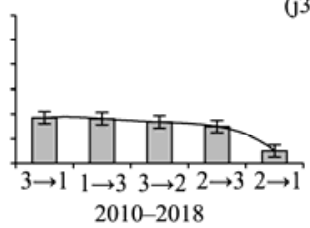

(a4)

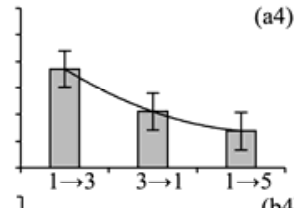

(b4)

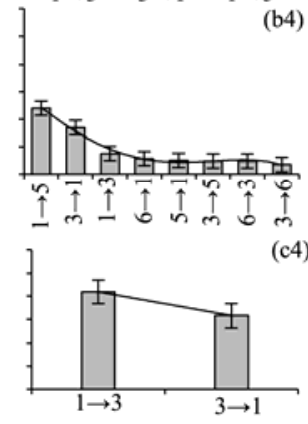

(d4)

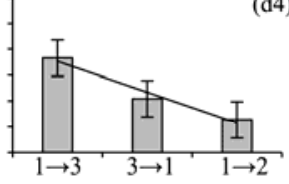

(e4)
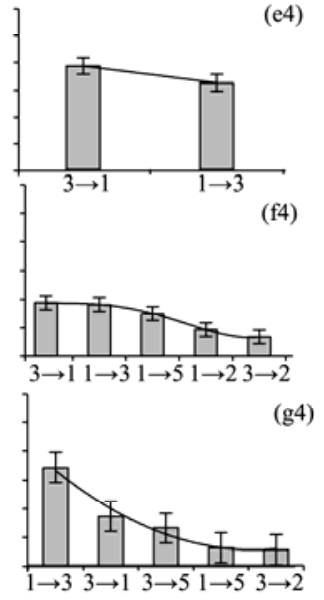

(h4)

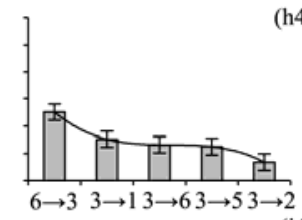

(i4)

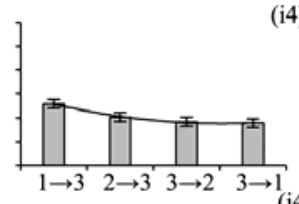

(j4)

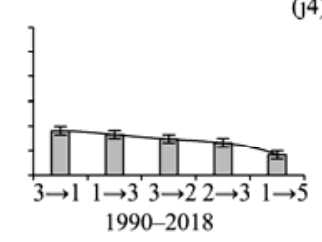

Fig. 4 Significance index of land cover change $\left(C_{i}\right)$ of different geomorphic units on the Chinese Loess Plateau in different periods. 1, cropland; 2 , forestland; 3, grassland; 4, wetland; 5 , construction land; 6 , unused land. Symbol ' $\rightarrow$ ' represents the conversion of land cover change. 
Generally, over the 28-year study period, significance indices of LBH and LVH were stable. For LT, RAP, SBH, SSH and SSM, their indices showed a smoothly descending trend. For LMH, the index showed a quickly descending trend. For LHIB, the index was stable followed by a quickly descending and then stable trend. For SLH, the index showed a quickly descending followed by stable trend.

3.2.2 Proportion index of land cover change

From 1990 to 2018, the proportion indices of land cover change in the 10 types of geomorphic units in the Loess Plateau significantly varied (Fig. 5). The proportion index of LVH was the largest $(D=23.32 \%)$, and the proportion index of SSM was the smallest $(D=10.50 \%)$. Average proportion index was $15.83 \%$ (Fig. 5d) over the 28-year study period. From 1990 to 2000, the land cover types in the 10 types of geomorphic units gently changed, and the proportion indices of LT, SBH, SSH, LBH, LHIB, RAP, SSM, LMH, SLH and LVH successively declined, with $D$ values of $4.29 \%, 3.49 \%, 1.88 \%, 1.82 \%, 1.66 \%, 1.21 \%, 1.00 \%, 0.83 \%, 0.76 \%$ and $0.68 \%$, respectively. Average proportion index in this period was 1.76\% (Fig. 5a). From 2000 to 2010, the proportion indices remarkably increased, and $D$ values were $11.89 \%$ for LT, $10.70 \%$ for SLH, $8.76 \%$ for $\mathrm{LMH}, 7.78 \%$ for $\mathrm{SBH}, 7.09 \%$ for RAP, $7.01 \%$ for $\mathrm{LBH}, 6.45 \%$ for $\mathrm{LVH}, 5.90 \%$ for LHIB, $4.69 \%$ for SSM and $4.53 \%$ for SSH (Fig. 5b). Average proportion index in this period was $7.48 \%$, which was $5.72 \%$ higher than that in the previous 10 years. From 2010 to 2018, the proportion indices of LT and SLH remarkably decreased, with $D$ values of $8.13 \%$ and $8.12 \%$, respectively. The proportion indices of the other 8 geomorphic units showed an increasing trend, and $D$ values were $19.50 \%$ for $\mathrm{LVH}, 12.75 \%$ for LHIB, $12.48 \%$ for RAP, $9.59 \%$ for $\mathrm{LBH}, 9.57 \%$ for $\mathrm{LMH}, 7.87 \%$ for $\mathrm{SBH}, 7.68 \%$ for $\mathrm{SSH}$ and $6.98 \%$ for SSM (Fig. 5c). Average proportion index in this period was $10.27 \%$, which was $2.79 \%$ higher than that in the previous 10 years.

(a) $1990-2000$

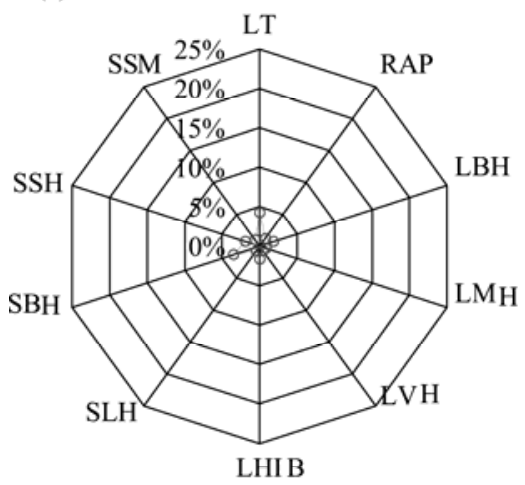

(c) 2010-2018

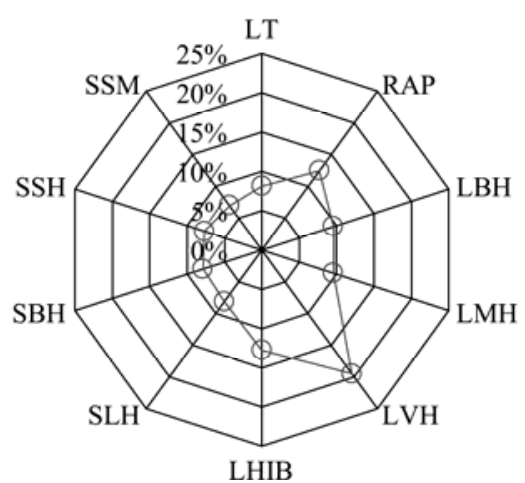

(b) 2000-2010

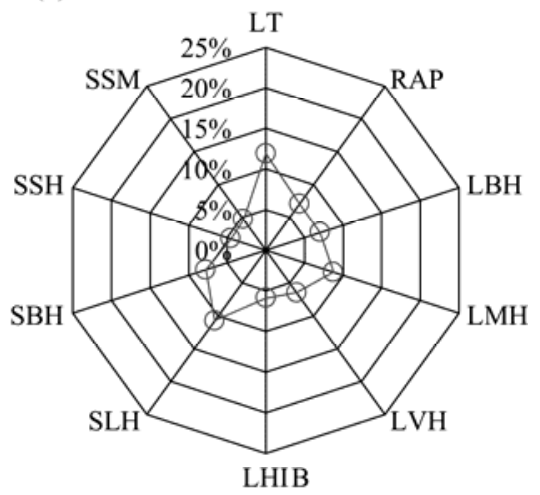

(d) 1990-2018

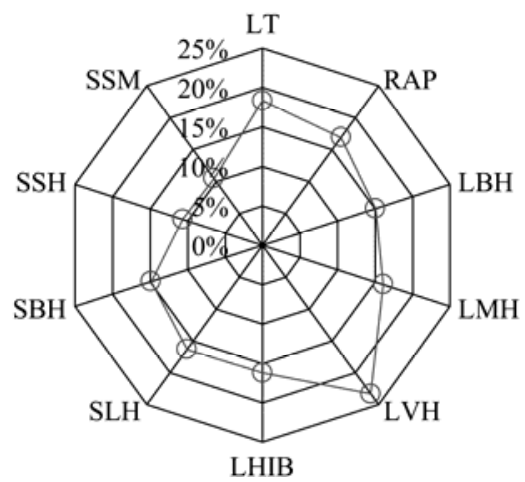

Fig. 5 Proportion index of land cover change $(D)$ of different geomorphic units on the Chinese Loess Plateau from 1990 to 2018 


\subsection{EQI}

The values of EQI in the Loess Plateau in 1990, 2000, 2010 and 2018 were $0.1506,0.1503$, 0.1504 and 0.1505 , respectively, and the EQI of different geomorphic units considerably varied (Table 3). The values of EQI in LBH, LMH, LVH, and SBH slightly increased, but they considerably decreased in LT, RAP and SLH. The values of EQI in LHIB, SSH and SSM slightly decreased. The EQI in SSH was the highest, followed by that in SSM, and that in SBH was the lowest.

Table 3 Eco-environmental quality index (EQI) of different geomorphic units on the Chinese Loess Plateau from 1990 to 2018

\begin{tabular}{cccccc}
\hline $\begin{array}{c}\text { Type of } \\
\text { geomorphic unit }\end{array}$ & EQI in 1990 & EQI in 2000 & EQI in 2010 & EQI in 2018 & Average EQI \\
\hline LT & 0.1488 & 0.1481 & 0.1474 & 0.1471 & 0.1478 \\
RAP & 0.1347 & 0.1333 & 0.1310 & 0.1315 & 0.1326 \\
LBH & 0.1328 & 0.1328 & 0.1363 & 0.1366 & 0.1347 \\
LMH & 0.1471 & 0.1483 & 0.1486 & 0.1476 & 0.1479 \\
LVH & 0.1242 & 0.1243 & 0.1266 & 0.1264 & 0.1254 \\
LHIB & 0.1602 & 0.1599 & 0.1606 & 0.1593 & 0.1600 \\
SLH & 0.1370 & 0.1368 & 0.1380 & 0.1350 & 0.1367 \\
SBH & 0.1082 & 0.1091 & 0.1084 & 0.1089 & 0.1087 \\
SSH & 0.2241 & 0.2227 & 0.2235 & 0.2237 & 0.2235 \\
SSM & 0.1981 & 0.1972 & 0.1977 & 0.1979 & 0.1977 \\
Total & 0.1506 & 0.1503 & 0.1504 & 0.1505 & 0.1505 \\
\hline
\end{tabular}

During the study period, the EQI of the Loess Plateau had apparent geomorphic differences, and there were three evolution types, i.e., deterioration, stability and improvement of EQI in each geomorphic unit (Fig. 6).

(a) $1990-2000$

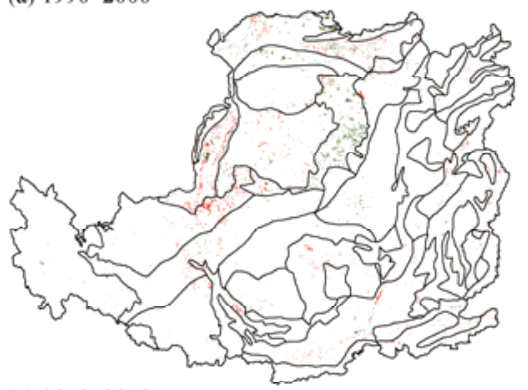

(c) 2010-2018

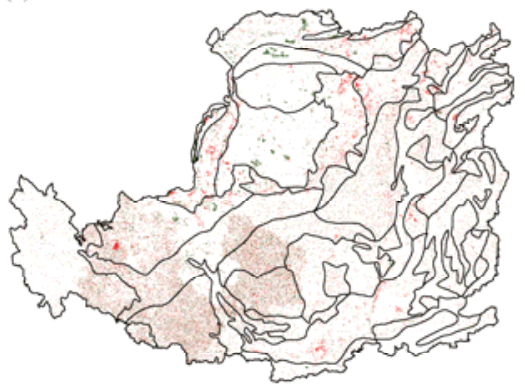

$0 \quad 150 \quad 300 \mathrm{~km}$

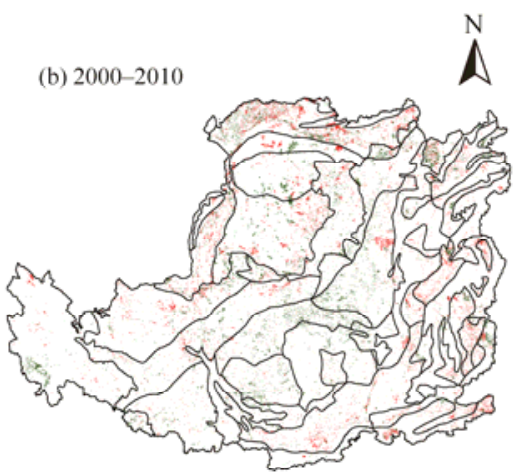

(d) 1990-2018

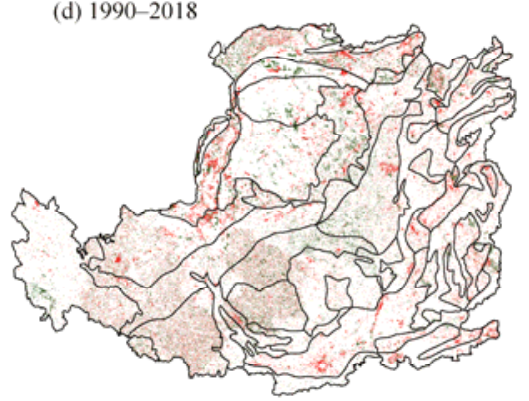

Legend

$\square$ Geomoraphic boundary

Deteriorated land

Stable land

Improved land

Fig. 6 Change in the eco-environment quality index of different geomorphic units on the Chinese Loess Plateau from 1990 to 2018 
From 1990 to 2000, the stable, deteriorated and improved areas of EQI accounted for 97.86\%, $1.30 \%$ and $0.83 \%$ of the total area of the Loess Plateau, respectively (Fig. 6a). Among the 10 geomorphic units, the proportions of deterioration and improvement of EQI in RAP were the largest ( $2.56 \%$ and $1.73 \%$, respectively). SBH had the second change proportion, with its proportions of deterioration and improvement being $1.69 \%$ and $1.80 \%$, respectively. The EQI of LBH was the most stable, and the proportions of deterioration and improvement were only $0.51 \%$ and $0.17 \%$, respectively.

From 2000 to 2010, stable, deteriorated and improved areas of EQI accounted for $92.53 \%, 3.65 \%$ and $3.81 \%$ of the total area of the Loess Plateau, respectively (Fig. 6b). The proportion of deteriorated area in RAP based on the EQI value was the largest $(7.46 \%)$, followed by that of in LHIB (5.69\%). The proportion of deteriorated area in SSH was the smallest (1.58\%). Proportion of improved area in LMH was the largest (5.57\%), followed by those of in LHIB and SLH $(5.01 \%$ and $4.99 \%$, respectively). Proportion of improved area in SSM was the smallest $(2.29 \%)$.

From 2010 to 2018, stable, deteriorated and improved areas of EQI accounted for $90.69 \%, 4.81 \%$ and $4.49 \%$ of the total area of the Loess Plateau, respectively (Fig. 6c). Proportion of deteriorated area in LBH was the largest $(9.50 \%)$, followed by that of in LVH $(6.31 \%)$. Proportion of deteriorated area in SSM was the smallest (3.50\%). Correspondingly, proportion of improved area in LBH was the largest $(10.01 \%)$, followed by that of in LVH $(6.45 \%)$. Proportion of improved area in LHIB was the smallest $(3.40 \%)$.

Overall, most of the areas in the Loess Plateau had stable EQI from 1990 to 2018, accounting for $84.83 \%$ of the total area. The areas that deteriorated or improved were similar in size, accounting for $7.90 \%$ and $7.27 \%$, respectively (Fig. 7d). Proportions of deteriorated area of EQI were $11.69 \%$ for RAP, $9.94 \%$ for LBH, $9.40 \%$ for LHIB, $8.42 \%$ for $\mathrm{LVH}, 7.91 \%$ for $\mathrm{LT}, 7.28 \%$ for SBH, $7.19 \%$ for $\mathrm{SLH}, 6.83 \%$ for LMH, 5.61\% for SSM and 5.09\% for SSH. Correspondingly, proportions of the improved area were $13.39 \%$ for $\mathrm{LBH}, 9.27 \%$ for $\mathrm{LMH}, 9.03 \%$ for $\mathrm{LT}, 7.90 \%$ for $\mathrm{SLH}, 7.80 \%$ for LVH, $7.58 \%$ for SBH, $6.93 \%$ for LHIB, $6.66 \%$ for RAP, $5.57 \%$ for SSH and $4.89 \%$ for SSM.

\section{Discussion}

\subsection{Geomorphic units and land cover change}

The geomorphic units in the Loess Plateau are complex and varied, and land cover pattern and evolution direction of different geomorphic units exhibit remarkable regional differences under the long-term effects of natural, social and economic factors (Luo et al., 2014; He et al., 2016). This study used geomorphology, the determinant of the direction of land cover change and the mode of vegetation restoration, as the basic research unit and analyzed the spatial variation trends and change characteristics of the land cover change of different geomorphic units at the regional scale. Compared with research on land cover changes that have used single topographical factors, such as elevation, slope and slope direction (Zhong et al., 2012; Li et al., 2013; Zhang et al., 2015; Li et al., 2016), this study revealed the relationship between geomorphology and land cover change in a relatively comprehensive manner, which will be helpful for evaluating the effects of ecological restoration projects, such as the conversion from cropland into forestland and grassland in the Loess Plateau, and for formulating targeted measures that optimize management of land use structure and for realizing a rational layout of land cover types of different geomorphic units.

The significance index of land cover change indicated that the dominant types of land cover change of the 5 geomorphic units (LT, LBH, LMH, SLH and SSH) from 1990 to 2018, were conversions from cropland into grassland, and mutual conversion between forestland and grassland. This result showed that conversions from cropland into grassland and forestland were the main directions of land cover change in the Loess Plateau and were closely related to the regional implementation of converting cropland into forestland and grassland and the other ecological construction projects (Liu et al., 2017; Zhang et al., 2017). The conversion from cropland into construction land was the main type of conversion in RAP that has a flat terrain and is densely populated. The construction of towns and mining and transportation facilities occupied a large area of the cropland. The conversion from grassland into cropland was the main types in LVH, LHIB and 
SSM. In the valleys of the Yellow River, the terrain is relatively flat, and the combination of soil and water resources is beneficial. Owing to the implementation of comprehensive small watershed management, the construction of warping dams, gully land consolidation and other ecological projects, the cropland area significantly increased. The conversion from unused land into grassland was the main type of land cover change in $\mathrm{SBH}$, which primarily benefited from the promotion of ecological protection and the sand control project, which accelerated the conversion from unused land into grassland. Generally, the land cover changes of different geomorphic units were related not only to the implementation time of the ecological construction projects but also to the local urban and rural construction in different periods, leading to spatial differences in land cover change (He et al., 2016; Liu et al., 2018).

The degree of proportion index of land cover change in the Loess Plateau from 1990 to 2000 was low, and mutual conversions between grassland and cropland and between grassland and unused land were the main types of land cover change. A probable reason is the household contract responsibility system that began in the 1980s, which effectively encouraged farming in the Loess Plateau. Many of the wastelands, grasslands and forestlands, especially wetlands and water bodies along the Yellow River, were extensively reclaimed for planting crops. The proportion index of land cover change and its degree in the Loess Plateau increased from 2000 to 2010. The reasons may be as follows: the implementation of two strategies including the West China Development Strategy and the Rise of Central China Strategy, resulted in the rapid expansion of regional urban land and large-scale exploitation of energy resources, accelerated the change rate of land utilization in the Loess Plateau and increased the area of construction land of different geomorphic units after 2000. However, the proportion indices in LT and SLH obviously decreased from 2010 to 2018, which indicated that the unstable tendency of land cover change was declining. This result can be attributed to the project of conversion from cropland into forest and grassland that resulted in the fewer disturbances from the human activities in the rural areas. Studies on the Qingjian River Basin (Guo et al., 2012) and the Hekou and Tongguan counties of the Yellow River (Luo et al., 2014), have also proven this finding.

\subsection{Government policy and land cover change}

Government policy had a profound impact on the types and changes of land utilization (Liu et al., 2014). Along with the implementation of the market economy, the industrialization and urbanization of the Loess Plateau rapidly developed, imposing direct impacts on the types of land utilization. During this process, a series of policies has been implemented to improve the deterioration of ecological environment (Fu, 2019; Jin, 2019).

At the beginning of 2000, the Returning Land from Farming to Forest policy was implemented, which resulted in lands with a slope $>25^{\circ}$ and drylands being converted into forestland and grassland. Meanwhile, the tax exemption on agricultural and grain subsidies were implemented in 2005, which led to the conversion from grasslands, unused lands and forestlands into cropland in RAP, LVH and RAP. In addition, the implementation of the National Food Security policy made croplands relatively stable in Ningxia Plain, Hetao Area of Inner Mongolia and Fenwei plains. The Main Functional Zones and the Constructing Ecological Civilizations policies were implemented in the Loess Plateau from 2010 to 2018 (Jin, 2019; Li et al., 2019). Large-scale ecological construction projects have restrained the reduction of forestland in natural forest regions, effectively expanded the areas of artificial forest, and inhibited grassland degradation in SBH and SLH, thus exerting a positive effect on regional ecological restoration and eco-environmental quality (Liu et al., 2014).

\subsection{Land cover change and eco-environmental quality}

The conversion of land cover types is an important driving force for the regional EQI change (Lu et al., 2013; Song et al., 2018). The deteriorated zones of EQI were mainly distributed in the major cities and towns of the Loess Plateau, including the Fenhe and Weihe river valleys, Yiluo Basin in western Henan, the central region in Inner Mongolia and the Yinchuan Plain in Ningxia. Disturbance intensity of human activities of these deteriorated zones is high, leading to the degradation of ecosystem. The improved zones were distributed in the northern part of Shaanxi, the Liupanshan 
Mountains in southern Ningxia, central and eastern Gansu and the Lüliang and Taihang mountains in Shanxi. Similar findings was given by Zhou et al. (2016), who found that the eco-environmental quality of the Loess Plateau worsened from the late 1980s to 2000 and improved from 2000 to 2008 . Kong et al. (2018) also found that the effect of ecological restoration was better during 2001-2013 than during 1991-2000 due to the significant increased vegetation coverage.

\subsection{Implications}

This study investigated the change in land cover and the evolution of its ecological environment based on the geomorphic data and land cover data on the Loess Plateau. We found that the overall eco-environmental quality was low in the Loess Plateau, which confirmed the effects of human activity factors and socioeconomic factors of different geomorphic units on the Chinese Loess Plateau. However, the topography and hydrology are not considered in this study and the results have certain limitations. Therefore, according to the actual situation in the Loess Plateau, we should fully consider the geomorphology, topography and wet and dry conditions, to reveal the internal relations among geomorphology, land cover change and eco-environmental quality. This study determined the relative ecological value of different land cover types and calculated ecological environment quality index based on coefficients of ecosystem service value of China's terrestrial ecosystem. However, with the development of urbanization and industrialization, the demand for ecological products by urban and rural residents has become increasingly diversified, and new changes have occurred in the land use types correspondingly. Therefore, scientific measurement of ecosystem service value and improvement of measured model of ecological environment quality need to be further studied and discussed.

\section{Conclusions}

This study found that the areas of forestland and construction land substantially increased, whereas those of cropland, grassland, wetland and unused land considerably decreased. Thirty land cover change types were observed, and the area accounted for $15.17 \%$ of the total area of the Chinese Loess Plateau. The main conversion of land cover change was from cropland into other land types. The unstable trend of land cover change in LT and SLH declined, and the proportion index of land cover change decreased, whereas the proportion index of the other geomorphic units increased. The eco-environmental quality of the Loess Plateau decreased and then improved, and the improvement was most obvious after 2000. The eco-environmental qualities of LT, LBH, LMH, SLH, SBH and SSH were notably improved, whereas those of RAP, LVH, LIHB and SSM were gradually deteriorated. The degradations of forestland, grassland and wetland, and the expansion of construction land were the main driving factors for the deterioration of eco-environmental quality. The conversion from cropland and unused land into grassland and forestland and the conversion from grassland into forestland were important driving factors for the improvement of eco-environmental quality.

\section{Acknowledgements}

This research was funded by the Special Project of the Ministry of Science and Technology of China (2014FY210100), the National Key Research and Development Program of China (2018YFD1100101) and the National Natural Science Foundation of China (41971204).

\section{References}

Bičík I, Kupková L, Jeleček L, et al. 2015. Land Use Changes in the Czech Republic 1845-2010. Switzerland: Springer, 95-170. Brierley G, Stankoviansky M. 2003. Geomorphic responses to land use change. Catena, 51(3-4): 173-179.

Bryan B A, Gao L, Ye Y Q, et al. 2018. China's response to a national land-system sustainability emergency. Nature, 559(7713): 193-204.

CAS (Chinese Academy of Sciences), CNGEC (China's Natural Geographic Editor Committee). 1980. China's Natural Geographical Landscape. Beijing: Science Press, 15-20. (in Chinese) 
Chen W T, Wang Y X, Li X J, et al. 2016. Land use/land cover change and driving effects of water environment system in Dunhuang Basin, northwestern China. Environmental Earth Sciences, 75: 1027.

CSNR (China Society of Natural Resources). 2018. Report on Advances in Resources Science (2016-2017). Beijing: China Science and Technology Press, 106-107. (in Chinese)

Deng L, Liu G B, Shangguan Z P. 2014. Land-use conversion and changing soil carbon stocksin China's 'Grain-for-Green' program: A synthesis. Global Change Biology, 20(11): 3544-3556.

Fu B J. 2019. The project of returning farmland to forests has enabled the Loess Plateau to achieve a "win-win" situation for ecological environmental protection and social economic development. Yan'an Daily, [2004-08-13]. (in Chinese)

Gao H D, Li Z B, Jia L L, et al. 2016. Capacity of soil loss control in the Loess Plateau based on soil erosion control degree. Journal of Geographical Sciences, 26(4): 457-472.

GAPRCEC (Geomorphologic Atlas of the People's Republic of China Editor Committee). 2009. The Geomorphologic Atlas of the People's Republic of China (1:1,000,000). Beijing: Science Press, 23. (in Chinese)

Ge Q S, Dai J H, He F N, et al. 2008. The research of land use/cover change and carbon cycle of China in the past 300 years. Science in China: Earth Science, 38(2):197-210. (in Chinese)

GLP (Global Land Project). 2005. Global land project: Science plan and implementation strategy. In: IGBP Report No. 53/IHDP Report No.19, IGBP Secretariat, Stockholm.

Guo B Y, Wang G Q, Fu X D, et al. 2012. Spatial structure and fractal model of land use in Qingjian river basin of middle Yellow River. Transaction of the Chinese Society of Agricultural Engineering, 28(14): 223-228. (in Chinese)

He W C, Zhao S M, Cheng W M. 2016. Analysis of land cover change on basic geomorphic types in Shanxi province. Journal of Geo-Information Science, 18(2): 210-219. (in Chinese)

Janssen L L F, Vander Welf F J M. Accuracy assessment of satellite derived land-cover data: A review. Photogram metric Engineering and Remote Sensing, 1994, 60: 419-426.

Jin Z. 2019. Ecological restoration and management in the Loess Plateau entering the new era. Journal of Earth Environment, 10(3): 316-322. (in Chinese)

Kalnay E, Cai M. 2003. Impact of urbanization and land-use change on climate. Nature, 423(6939): 528-531.

Kong D X, Miao C Y, Borthwick A G L, et al. 2018. Spatiotemporal variations in vegetation cover on the Loess Plateau, China, between 1982 and 2013: possible causes and potential impacts. Environmental Science and Pollution Research, 25(14): 13633-13644.

Lambin E F, Baulies X, Bockstael N, et al. 1995. Land-use and land-cover change (LUCC): Implementation strategy. In: A core project of the International Geosphere-Biosphere Programme and the International Human Dimensions Programme on Global Environmental Change. IGBP Report 48. IHDP Report 10. IGBP, Stockholm, 125.

Lawler J J, Lewis J D, Nelson E, et al. 2014. Projected land-use change impacts on ecosystem services in the United States. Proceedings of the National Academy of Sciences, 111(20): 7492-7497.

Li J J, Li Z, Lü Z M. 2016. Analysis of spatiotemporal variations in land use on the Loess Plateau of China during 1986-2010. Environmental Earth Sciences, 75(11): 2-12.

Li Z, Liu W Z, Zheng F L. 2013. The land use changes and its relationship with topographic factors in the Jing river catchment on the Loess Plateau of China. Springer Plus, 2(S1): S3.

Liu G B, Shangguan Z P, Yao W Y, et al. 2017. Ecological effects of soil conservation in Loess Plateau. Bulletin of Chinese Academy of Sciences, 32(1): 11-19. (in Chinese)

Liu J F, Sun H, Chang G Q, et al. 2014. Research on national investment policy and mechanism of ecological security in the Loess Plateau. Soil and Water Conservation, (4): 23-27. (in Chinese)

Liu J Y, Kuang W H, Zhang Z X, et al. 2014. Spatiotemporal characteristics, patterns, and causes of land-use changes in China since the late 1980s. Journal of Geographical Sciences. 24 (2): 195-210.

Liu M X, Zhao R D, Shao P, et al. 2018. Temporal and spatial variation of vegetation coverage and its driving forces in the Loess Plateau from 2001 to 2015. Arid Land Geography, 41(1): 99-108. (in Chinese)

Lv L G, Zhou S L, Zhou B B, et al. 2013. Land use transformation and its eco-environmental response in process of the regional development: A case study of Jiangsu province. Scientia Geographica Sinica, 33(12): 1442-1449. (in Chinese)

Luo Y, Yang S T, Liu X Y, et al. 2014. Land use change in the reach from Hekouzhen to Tongguan of the Yellow River during 1998-2010. Acta Geographic Sinica, 69(1): 42-53.

Mayer W B, Turner B L. 1994. Changes in Land Use and Land Cover: A Global Perspective. New York: Cambridge University Press, 537-538.

Mooney H A, Duraiappah A, Larigauderie A. 2013. Evolution of natural and social science interactions in global change research programs. Proceedings of the National Academy of Sciences, 110(Suppl. 1): 3665-3672. 
Ning J, Liu J Y, Kuang W H, et al. 2018. Spatiotemporal patterns and characteristics of land-use change in China during 2010-2015. Journal of Geographical Sciences, 28(5): 547-562.

Reid W V, Chen D, Goldfarb L, et al. 2010. Earth system science for global sustainability: grand challenges. Science, 330(6006): 916-917.

Shi H, Shao M. 2000. Soil and water loss from the Loess Plateau in China. Journal of Arid Environments, 45(1): 9-20.

Song W, Deng X Z. 2017. Land-use/land-cover change and ecosystem service provision in China. Science of the Total Environment, 576: 705-719.

Song Y Y, Xue D Q, Dai L H, et al. 2018. Land use change and its ecological response in typical fossil energy development zones of Shanxi-Shaanxi-Inner Mongolia. Arid Zone Research, 35(5): 1-9. (in Chinese)

Turner B L, Skole D, Sanderson S, et al. 1995. Land use and land cover change science/research plan. In: IGBP Report No.35, IHDP Report 7. Stockholm, Geneva, 61-78.

Turner B L, Lambin E F, Reenberg A. 2007. The emergence of land change science for global environmental change and sustainability. Proceeding of the National Academy of Sciences, 104(52): 20666-20671.

Verbuerg P H, Chen Y Q. 2000. Multiscale characterization of land use patterns in China. Ecosystems, 3(4): 369-385.

Waisanen P J, Bliss N B. 2002. Changes in population and agricultural land in conterminous United States counties, 1790 to1997. Global Biogeochemical Cycle, 16(4): 1-15.

Wang S, Fu B J, Piao S L, et al. 2016. Reduced sediment transport in the Yellow River due to anthropogenic changes. Nature Geoscience, 9(1): 38-41.

Wu L N, Yang S T, Liu X Y, et al. 2014. Response analysis of land use change to the degree of human activities in Beiluo River basin since 1976. Acta Geographica Sinica, 69(1): 54-63. (in Chinese)

Xie G D, Lu C X, Leng Y F, et al. 2003. Ecological assets valuation of the Tibetan Plateau. Journal of Natural Resources, 18(2): 189-196. (in Chinese)

Zhang J X, Zhang D Y, Zhang B, et al. 2015. Vegetation landscape change and its multi-scale response relationship with terrain in Loess Plateau. Chinese Journal of Ecology, 34(3): 611-620. (in Chinese)

Zhang K, Lü Y H, Fu B J. 2017. Vegetation restoration and its influences on ecosystem services in areas typical of the Loess Plateau. Journal of Ecology and Rural Environment, 33(1): 23-31. (in Chinese)

Zhang X R, Liu L P, Fang S, et al. 2014. Research advances on the relationship between land use/cover change and environmental change. Ecological and Environment Science, 23(12): 2013-2021. (in Chinese)

Zhao G, Mu X, Wen Z, et al. 2013. Soil erosion, conservation, and eco-environment changes in the Loess Plateau of China. Land Degradation and Development, 24(5): 499-510.

Zhao M, Cheng W M, Huang K, et al. 2016. Research on land cover change in Beijing-Tianjin-Hebei region during the last 10 years based on different geomorphic units. Journal of Natural Resources, 31(2): 251-264. (in Chinese)

Zhong D Y, Chang Q R, Song F J. 2012. Relationship between terrain factors and spatial distribution of land use hilly and gully area. Journal of Arid Land Resources and Environment, 26(6): 102-107. (in Chinese)

Zhou S G, Shao Q Q, Cao W. 2016. Characteristics of land use and land cover change in the Loess Plateau over the past 20 years. Journal of Geo-Information Science, 18(2): 190-199. (in Chinese) 